\title{
Hot Spots of Phytoene Desaturase from Rhodobacter sphaeroides Influencing the Desaturation of Phytoene
}

\author{
Bo Hyun Choi, Sung Hui Kim and Pyung Cheon Lee *D \\ Department of Molecular Science and Technology, Ajou University, World cup-ro, Yeongtong-gu, \\ Suwon-si 16499, Korea; bohyunho0@ajou.ac.kr (B.H.C.); sunghui06@naver.com (S.H.K.) \\ * Correspondence: pclee@ajou.ac.kr; Tel.: +82-31-219-2461
}

check for updates

Citation: Choi, B.H.; Kim, S.H.; Lee, P.C. Hot Spots of Phytoene

Desaturase from Rhodobacter

sphaeroides Influencing the

Desaturation of Phytoene. Catalysts 2021, 11, 1248. https://doi.org/

$10.3390 /$ catal11101248

Academic Editors:

Edinson Yara-Varón and

Ramon Canela-Garayoa

Received: 29 September 2021

Accepted: 16 October 2021

Published: 18 October 2021

Publisher's Note: MDPI stays neutral with regard to jurisdictional claims in published maps and institutional affiliations.

Copyright: (C) 2021 by the authors. Licensee MDPI, Basel, Switzerland. This article is an open access article distributed under the terms and conditions of the Creative Commons Attribution (CC BY) license (https:/ / creativecommons.org/licenses/by/ $4.0 /)$.

\begin{abstract}
Phytoene desaturase (CrtI, E.C. 1.3.99.31) shows variable desaturation activity, thereby introducing different numbers of conjugated double bonds (CDB) into the substrate phytoene. In particular, Rhodobacter sphaeroides CrtI is known to introduce additional 6 CDBs into the phytoene with $3 \mathrm{CDBs}$, generating neurosporene with $9 \mathrm{CDBs}$. Although in-depth studies have been conducted on the function and phylogenetic evolution of CrtI, little information exists on its range of CDB-introducing capabilities. We investigated the relationship between the structure and CDB-introducing capability of CrtI. CrtI of R. sphaeroides KCTC 12085 was randomly mutagenized to produce carotenoids of different CDBs (neurosporene for 9 CDBs, lycopene for 11 CDBs, and 3,4-didehydrolycopene for $13 \mathrm{CDBs}$ ). From six CrtI mutants producing different ratios of neurosporene/lycopene/3,4-didehydrolycopene, three amino acids (Leu163, Ala171, and Ile454) were identified that significantly determined carotenoid profiles. While the L163P mutation was responsible for producing neurosporene as a major carotenoid, A171P and I454T produced lycopene as the major product. Finally, according to the in silico model, the mutated amino acids are gathered in the membrane-binding domain of CrtI, which could distantly influence the FAD binding region and consequently the degree of desaturation in phytoene.
\end{abstract}

Keywords: phytoene desaturase; CrtI; Rhodobacter sphaeroides; random mutagenesis

\section{Introduction}

Carotenoids are a diverse group of colored isoprenoid derivatives that play distinct roles in nature [1]. More than 800 different carotenoids are synthesized in photosynthetic microorganisms, plants, and animals [2]. Naturally occurring carotenoids and their biosynthetic pathways are classified as C30, C40, and C50 based on the carbon numbers of their backbone structures [3]. Carotenoids serve several biological functions, including in coloration, photoprotective activities, and light harvesting, and are also the precursors for several plant hormones [4-6]. Carotenoids are widely used in the food, medical, pharmaceutical, and cosmetic industries as colorants and functional ingredients [7,8]. Despite the structural diversity and commercial importance of carotenoids, only a few simplestructured carotenoids, such as $\beta$-carotene and lycopene, are produced commercially by chemical synthesis or isolation. Their increasing industrial importance has led to renewed efforts to develop bioprocesses for the production of diverse carotenoids [8-10].

Rhodobacter sphaeroides is a Gram-negative purple bacterium that produces cellular energy through photosynthesis and synthesizes a C40 carotenoid spheroidene [11] through sequential reactions with seven pathway enzymes: geranylgeranyl diphosphate (GGPP) synthase (CrtE), phytoene synthase (CrtB), phytoene desaturase (CrtI), spheroidene monooxygenase (CrtA), methoxy-neurosporene desaturase (CrtD), hydroxy-neurosporene synthase ( $\mathrm{CrtC})$, and hydroxyneurosporene-O-methyltransferase ( $\mathrm{CrtF})$. R. sphaeroides is a well-known carotenogenic bacterium similar to Pantoea agglomerans, which was previously classified as Erwinia herbicola [12], and its carotenogenic pathway has been widely used as a model system [13]. 
In cyanobacteria and plants, a complex and multi-component pathway is employed by phytoene desaturase (PDS), $\zeta$-carotene desaturase (ZDS), carotene cis-trans isomerase (CRTISO), and $\zeta$-carotene cis-trans isomerase (Z-ISO) for desaturation of 15-cis-phytoene to all-trans-lycopene [14-16]. In contrast, bacteria and fungi employ a sole CrtI to generate all-trans-lycopene from 15-cis-phytoene [17]. During the catalytic desaturation reaction, CrtI uses flavin adenine dinucleotide (FAD) as an electron shuttle and oxygen as the acceptor [18]. In nature, C40 carotenoid structures have been diversified by CrtI, with different desaturation activities for 15-cis-phytoene. Depending on the carotenogenic microorganisms, CrtI can catalyze either a 3-step, 4-step, or 5-step desaturation reaction of 15-cisphytoene, which is synthesized by CrtB from two moles of GGPP (Figure 1a). R. sphaeroides CrtI catalyzes 3-step desaturation, P. agglomerans CrtI catalyzes 4-step desaturation [19], and Neurospora crassa CrtI catalyzes 5-step desaturation [20]. The neurosporene with 9 conjugated double bonds (CDBs), lycopene with $11 \mathrm{CDBs}$, and 3,4-didehydrolycopene with 13 CDBs (or tetradehydrolycopene with $15 \mathrm{CDBs}$ ) are end-products in desaturation reactions, whereby 15-cis-phytoene is sequentially desaturated by different catalytic activities of CrtIs (Figure 1b). Most carotenogenic enzymes, including CrtI, can be functionally expressed in Escherichia coli; therefore, E. coli is a convenient heterologous host for the production of diverse carotenoids [21-25]. To date, several studies have considered the catalytic mechanism of CrtI (or PDS) in E. coli and native host strains. Our understanding of substrate binding sites, potential catalytic residues, and recognition regions of the hydrocarbon substrate is based largely on the crystal structure of the plant-type phytoene desaturase PDS via in silico docking experiments [26]; however, the exact mechanism for the desaturation process is still unclear.

a

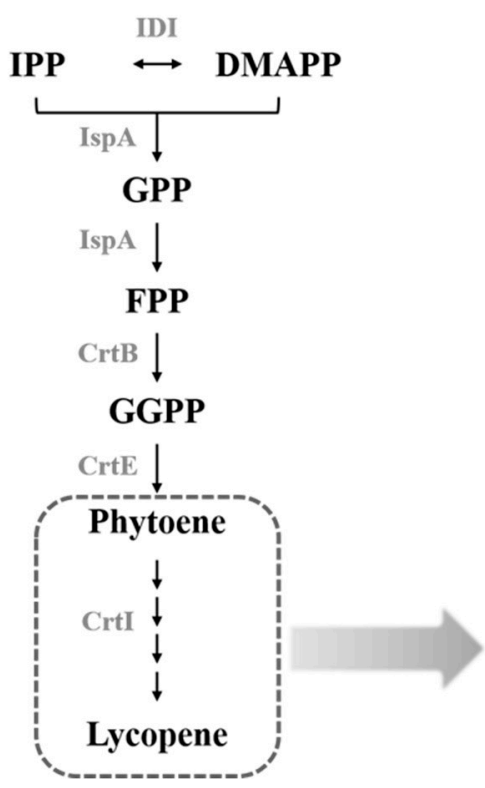

b

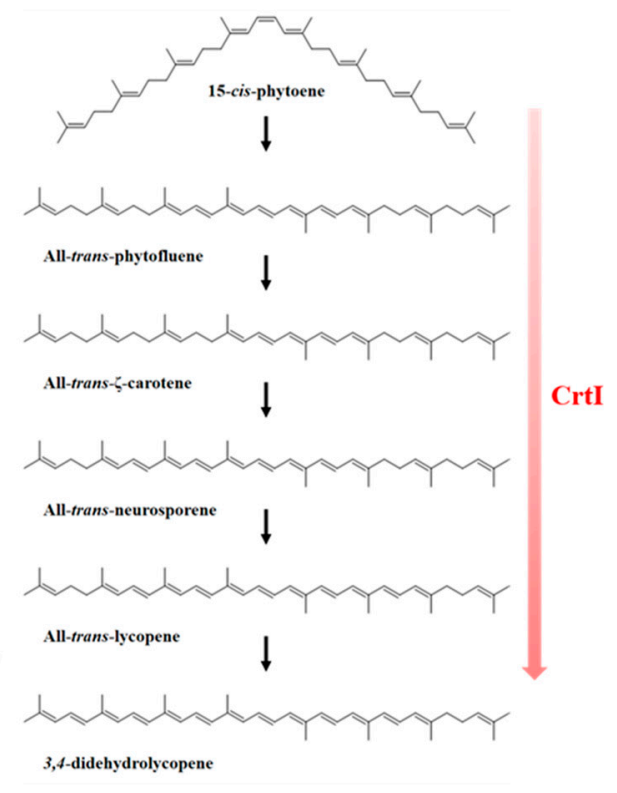

Figure 1. The lycopene biosynthesis pathway and phytoene desaturation catalyzed by phytoene desaturase (CrtI): (a) lycopene biosynthesis pathway in recombinant Escherichia coli; (b) phytoene desaturation catalyzed by CrtI from Rhodobacter sphaeroides. Metabolite abbreviations: IPP, isopentenyl diphosphate; DMAPP, dimethylallyl diphosphate; GPP, geranyl diphosphate; FPP, farnesyl diphosphate; GGPP, geranylgeranyl diphosphate. Pathway enzymes: IDI, isopentenyl diphosphate isomerase; IspA, farnesyl diphosphate synthase; $\mathrm{CrtB}$, geranylgeranyl diphosphate synthase; $\mathrm{CrtE}$, phytoene synthase; $\mathrm{CrtI}$, phytoene desaturase. The dotted line indicates the multi-step desaturation process of phytoene to lycopene.

In the present study, R. sphaeroides CrtI was mutated using random mutagenesis to introduce different degrees of desaturation in phytoene in an E. coli strain expressing 
R. sphaeroides CrtE and CrtB. Next, altered amino acids in the evolved CrtI mutants were analyzed in silico to investigate the relationship between the structural changes caused by mutated amino acids and phytoene desaturation.

\section{Results}

2.1. Reconstruction of Lycopene Biosynthesis Pathways and Directed Evolution of the R. sphaeroides Phytoene Desaturase (CrtI)

Three lycopene synthetic genes encoding $\mathrm{CrtE}_{\mathrm{RS} / \mathrm{PA}}, \mathrm{CrtB}_{\mathrm{RS} / \mathrm{PA}}$, and $\mathrm{CrtI} \mathrm{I}_{\mathrm{RS} / \mathrm{PA}}$ from $R$. sphaeroides and P. agglomerans were modified to be modularly expressed and then coexpressed on plasmids in E. coli [26,27]. R. sphaeroides produces neurosporene from phytoene through a 3-step desaturation reaction catalyzed by $\mathrm{CrtI}_{\mathrm{RS}}$; however, a recombinant $E$. coli coexpressing $\mathrm{CrtE}_{\mathrm{RS}}, \mathrm{CrtB}_{\mathrm{RS}}$, and $\mathrm{Crt} \mathrm{I}_{\mathrm{RS}}$ as an individual expression module (pUCM_I $\mathrm{RS}+$ pACM_E $\mathrm{E}_{\mathrm{RS}} \mathrm{B}_{\mathrm{RS}}$ ) produced further desaturated lycopene (11 CDBs, $30.7 \pm 7.1 \%$ ), 3,4-didehydrolycopene (13 CDBs, $4 \pm 2.7 \%$ ), as well as neurosporene (9 CDBs, $66 \pm 10.1 \%$ ) (Figure 2a). On the other hand, coexpression of $\mathrm{CrtI}_{\mathrm{RS}}$ with heterologous $\mathrm{CrtE}_{\mathrm{PA}}$ and $\mathrm{CrtB} \mathrm{P}_{\mathrm{PA}}\left(\mathrm{pUCM} \mathrm{I}_{\mathrm{RS}}+\mathrm{pACM} \mathrm{E}_{\mathrm{PA}} \mathrm{B}_{\mathrm{PA}}\right)$ produced neurosporene $(73.4 \pm 3.7 \%)$ and lycopene (27.6 $\pm 4.7 \%)$, without formation of 3,4-didehydrolycopene (Figure $2 \mathrm{~b}$ ). This suggests that the heterologous carotenogenic enzyme complex can influence the desaturation of phytoene.

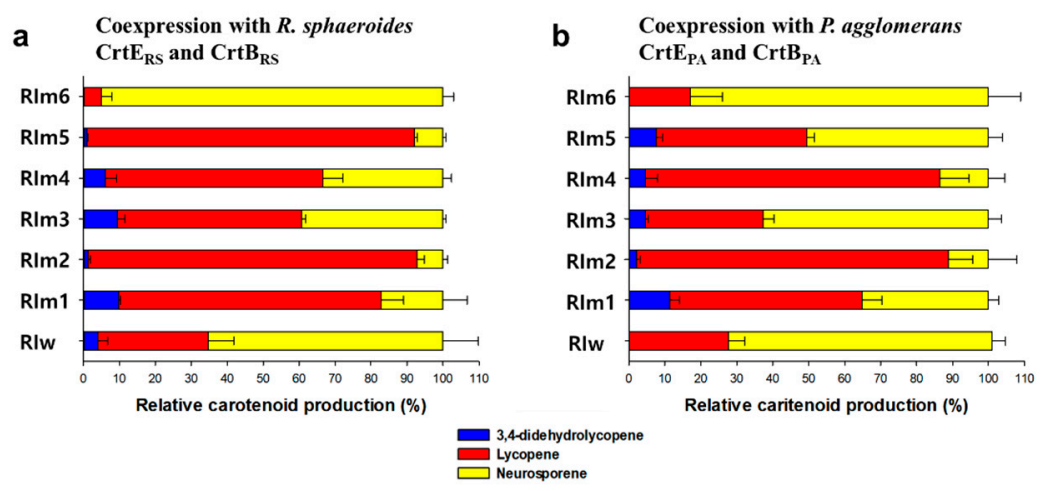

Figure 2. Relative carotenoid profiles in E. coli strains coexpressing six $\mathrm{CrtI}_{\mathrm{RS}}$ mutants with (a) R. sphaeroides $\mathrm{CrtE}_{\mathrm{RS}}$ and $\mathrm{CrtB}_{\mathrm{RS}}$ and (b) P. agglomerans $\mathrm{CrtE}_{\mathrm{PA}}$ and $\mathrm{CrtB}_{\mathrm{PA}}$. Blue, red, and yellow bars represent 3,4-didehydrolycopene, lycopene, and neurosporene, respectively. RIw refers to a wild-type $\mathrm{CrtI}_{\mathrm{RS}}$. Data are expressed as the mean $\pm \mathrm{SD}$.

Random mutation of the $c r t I_{R S}$ gene was performed using PCR-based mutagenesis [28], and the resulting mutant $\operatorname{crt}_{\mathrm{RS}}$ genes were transformed and coexpressed in a recombinant $E$. coli expressing the $R$. sphaeroides $\mathrm{CrtE}_{\mathrm{RS}}$ and $\mathrm{CrtB}_{\mathrm{RS}}$ as PACM_E $\mathrm{E}_{\mathrm{RS}} \mathrm{B}_{\mathrm{RS}}$ (Table 1). From a colony library of approximately 10,000 colonies, colonies of dissimilar colors were visually screened, isolated, and analyzed. Among yellow (background carotenogenic clones) and white colonies (non-carotenogenic clones, due to inactivated $\mathrm{CrtI}_{\mathrm{RS}}$ ), two red colonies, named RIm1 and RIm2, were selected, and carotenoid profiles of the clones were investigated by high-performance liquid chromatography (HPLC). RIm1 and RIm2 mutant clones produced significantly different carotenoid profiles: neurosporene $(17.2 \pm 6.7 \%)$, a major lycopene $(72.9 \pm 6.3 \%)$, and 3,4-didehydrolycopene $(9.9 \pm 0.4 \%)$ in $\operatorname{RIm} 1$ vs. neurosporene $(7.2 \pm 1.3 \%)$, a major lycopene $(91.5 \pm 2.0 \%)$, and 3,4-didehydrolycopene $(1.3 \pm 0.7 \%)$ in RIm2 mutant (Figure $2 \mathrm{a}$ and Table 2). Interestingly, one weak yellow colony (RIm6) produced a major neurosporene $(95 \pm 3.1 \%)$ and a small amount of lycopene (5.3 $\pm 2.4 \%$ ) (Figure $2 \mathrm{a}$ and Table 2$)$. Next, a 2nd round of random mutagenesis of RIm1 and RIm2 was carried out to generate the 2nd colony library of ca. 10,000 colonies. Among the 2nd library, two deep pink colonies (RIm3 and RIm4) from the parental RIm1 and one weak pink colony (RIm5) from the parental RIm2 were selected. HPLC analysis revealed that the mutants $\mathrm{RIm} 3, \mathrm{RIm} 4$, and $\mathrm{RIm} 5$ also showed unique carotenoid profile variations with a major lycopene $(51.2 \pm 1.2 \%$ in $\operatorname{RIm} 3,60.5 \pm 5.5 \%$ 
in $\operatorname{RIm} 4$, and $90.8 \pm 0.9 \%$ in $\operatorname{RIm} 5)$, followed by neurosporene $(39.4 \pm 0.9 \%$ in $\operatorname{RIm} 3$, $33.4 \pm 2.4 \%$ in $\operatorname{RIm} 4$, and $8.1 \pm 0.9 \%$ in $\operatorname{RIm} 5)$ and 3,4-didehydrolycopene $(9.4 \pm 2.1 \%$ in RIm3, $6.2 \pm 3.2 \%$ in RIm4, and $1.1 \pm 0.1 \%$ in RIm5) (Figure 2a and Table 2).

Table 1. Strains and plasmids used in this study.

\begin{tabular}{|c|c|c|}
\hline Plasmid & Description & $\begin{array}{l}\text { Source or } \\
\text { Reference }\end{array}$ \\
\hline \multicolumn{3}{|l|}{ Strains } \\
\hline $\begin{array}{c}\text { Rhodobacter sphaeroides } \\
\text { Pantoea agglomerans }\end{array}$ & Microbial source for $\mathrm{C}_{40}$ carotenoid pathway genes & $\begin{array}{c}\text { КСТС } 12085 \\
\text { КСТС } 2479 \\
\end{array}$ \\
\hline \multicolumn{3}{|l|}{ Plasmids } \\
\hline pGEM $^{\circledR}$ T-easy vector & Cloning vector & Promega \\
\hline pT_crtE & Vector containing crtE gene from $R$. sphaeroides & This study \\
\hline pT_crtBRS & Vector containing $\operatorname{crtB}$ gene from $R$. sphaeroides & This study \\
\hline pT_crtI & Vector containing crtI gene from $R$. sphaeroides & This study \\
\hline pUCM & Cloning vector modified from pUC19. constitutive lac promoter, Amp & [8] \\
\hline pUCM_ERS & Constitutively expressed crtE gene from $R$. sphaeroides & This study \\
\hline pUCM_B B & Constitutively expressed $c r t B$ gene from $R$. sphaeroides & This study \\
\hline pUCM_I & Constitutively expressed $c r t I$ gene from $R$. sphaeroides & This study \\
\hline pACM_E & Constitutively expressed $c r t E$ gene from $R$. sphaeroides & This study \\
\hline pACM_E ES_B ${ }_{R S}$ & Constitutively expressed $c r t E$ and $c r t B$ genes from $R$. sphaeroides & This study \\
\hline pACM_EPA_BPA & Constitutively expressed $c r t E$ and $c r t B$ genes from $P$. agglomerans & [22] \\
\hline pUCM_IRS_Im1 & Constitutively expressed mutant crtI gene (I454T) & This study \\
\hline pUCM_I IS_Im2 & Constitutively expressed mutant $\mathrm{crtI}$ gene (A171P) & This study \\
\hline pUCM_IRS_Im3 & Constitutively expressed mutant $c r t I$ gene (I454T and E186G) & This study \\
\hline pUCM_I IS_Im4 & Constitutively expressed mutant crtI gene (I454T and L429L) & This study \\
\hline pUCM_I IS_Im5 & Constitutively expressed mutant $\operatorname{crtI}$ gene (A171P and W142R) & This study \\
\hline pUCM_I IS_Im6 & Constitutively expressed mutant crtI gene (L163P) & This study \\
\hline pUCM_I IS_ImA171P & Constitutively expressed mutant $\operatorname{crtI}$ (Site-directed mutation) & This study \\
\hline pUCM_I ${ }_{\text {RS_ImL163P }}$ & Constitutively expressed mutant $\mathrm{crtI}$ (Site-directed mutation) & This study \\
\hline pUCM-I RS_ImW142R & Constitutively expressed mutant $\mathrm{crtI}$ (Site-directed mutation) & This study \\
\hline pUCM-I RS_ImE186G & Constitutively expressed mutant $c r t I$ (Site-directed mutation) & This study \\
\hline pUCM-I ${ }_{\text {RS_ImI } 454 T}$ & Constitutively expressed mutant $c r t I$ (Site-directed mutation) & This study \\
\hline pUCM-I ${ }_{R S}$ ImA171P\&I454T & Constitutively expressed mutant $c r t I$ (Site-directed mutation) & This study \\
\hline
\end{tabular}

Table 2. $\mathrm{CrtI}_{\mathrm{RS}}$ mutants generated by random mutagenesis and altered carotenoid profiles when complemented with the R. sphaeroides $\mathrm{CrtB}_{\mathrm{RS}}$ and $\mathrm{CrtE}_{\mathrm{RS}}$ and the P. agglomerans $\mathrm{CrtB}_{\mathrm{PA}}$ and $\mathrm{CrtE}_{\mathrm{PA}} \cdot{ }^{*} \mathrm{Neu}$, neurosporene; Lyc, lycopene; Ddl, didehydrolycopene. Proportions reported in parentheses: relative ratio of carotenoid profiles.

\begin{tabular}{|c|c|c|c|c|c|}
\hline Mutants & $\begin{array}{l}\text { Parental } \\
\text { Gene }\end{array}$ & $\begin{array}{l}\text { Nucleotide } \\
\text { Changes }\end{array}$ & $\begin{array}{l}\text { Amino Acid } \\
\text { Changes }\end{array}$ & $\begin{array}{l}\text { Carotenoid Profiles with } \\
\text { CrtE }_{R S} \text { and CrtB }\end{array}$ & $\begin{array}{c}\text { Carotenoid } \\
\text { Profiles with CrtE } \text { PA }_{P A} \text { and } \mathrm{CrtB}_{\mathrm{PA}}\end{array}$ \\
\hline $\mathrm{RIm} 1$ & WT & $\begin{array}{c}\text { T1361C } \\
(\mathrm{ATC} \rightarrow \mathrm{ACC})\end{array}$ & $\mathrm{I} 454 \mathrm{~T}$ & $\begin{array}{c}{ }^{*} \operatorname{Ddl}(9.9 \%) \\
\text { Lyc }(72.9 \%) \\
\text { Neu }(17.2 \%)\end{array}$ & $\begin{array}{c}\text { Ddl }(11.3 \%) \\
\text { Lyc }(53.5 \%) \\
\text { Neu }(35.1 \%)\end{array}$ \\
\hline $\operatorname{RIm} 2$ & WT & $\begin{array}{c}\mathrm{G} 511 \mathrm{C} \\
(\mathrm{GCC} \rightarrow \mathrm{CCC})\end{array}$ & A171P & $\begin{array}{l}\text { Ddl }(1.3 \%) \\
\text { Lyc }(91.5 \%) \\
\text { Neu }(7.2 \%)\end{array}$ & $\begin{array}{c}\text { Ddl }(2.1 \%) \\
\text { Lyc }(86.7 \%) \\
\text { Neu }(11.2 \%)\end{array}$ \\
\hline RIm3 & RIm1 & $\begin{array}{c}\text { T1361C } \\
(\mathrm{ATC} \rightarrow \mathrm{ACC}) \\
\text { A557G } \\
(\mathrm{GAG} \rightarrow \mathrm{GGG})\end{array}$ & $\begin{array}{l}\text { I454T } \\
\text { E186G }\end{array}$ & $\begin{array}{c}\text { Ddl }(9.4 \%) \\
\text { Lyc }(51.2 \%) \\
\text { Neu }(39.4 \%)\end{array}$ & $\begin{array}{c}\text { Ddl }(4.7 \%) \\
\text { Lyc }(32.6 \%) \\
\text { Neu }(62.7 \%)\end{array}$ \\
\hline $\mathrm{RIm} 4$ & RIm1 & $\begin{array}{c}\text { T1361C } \\
(\mathrm{ATC} \rightarrow \mathrm{ACC}) \\
\text { C1287T } \\
(\mathrm{CTC} \rightarrow \mathrm{CTT})\end{array}$ & $\begin{array}{c}\text { I454T } \\
\text { Silent mutation }\end{array}$ & $\begin{array}{c}\text { Ddl }(6.2 \%) \\
\text { Lyc }(60.5 \%) \\
\text { Neu }(33.4 \%)\end{array}$ & $\begin{array}{c}\text { Ddl }(4.6 \%) \\
\text { Lyc }(82.0 \%) \\
\text { Neu }(13.4 \%)\end{array}$ \\
\hline RIm5 & $\mathrm{RIm} 2$ & $\begin{array}{c}\text { G511C } \\
(\mathrm{GCC} \rightarrow \mathrm{CCC}) \\
\mathrm{T} 424 \mathrm{~A} \\
(\mathrm{TGG} \rightarrow \mathrm{AGG})\end{array}$ & $\begin{array}{l}\text { A171P } \\
\text { W142R }\end{array}$ & $\begin{array}{l}\text { Ddl }(1.1 \%) \\
\text { Lyc }(90.8 \%) \\
\text { Neu }(8.1 \%)\end{array}$ & $\begin{array}{l}\text { Ddl }(7.6 \%) \\
\text { Lyc }(41.9 \%) \\
\text { Neu }(50.5 \%)\end{array}$ \\
\hline RIm6 & WT & $\begin{array}{c}\mathrm{T} 488 \mathrm{C} \\
(\mathrm{CTG} \rightarrow \mathrm{CCG})\end{array}$ & L163P & $\begin{array}{c}\text { Ddl }(0 \%) \\
\text { Lyc }(5.3 \%) \\
\text { Neu }(94.7 \%)\end{array}$ & $\begin{array}{c}\text { Ddl }(0 \%) \\
\text { Lyc }(0 \%) \\
\text { Neu }(100 \%)\end{array}$ \\
\hline
\end{tabular}




\subsection{Identification of Mutation in Mutant Crtirs by Sequencing Analysis}

To reveal the genetic alterations of the six mutant $\mathrm{CrtI}_{\mathrm{RS}}$, genes encoding $\mathrm{RIm} 1$, RIm2, RIm3, RIm4, RIm5, and RIm6 were sequenced using the Sanger method (Table 2). A single-nucleotide point mutation was found in RIm1 and RIm2, causing an I454T amino acid change and an A171P change, respectively. To confirm the effect of the single I454T and A171P mutations on the degree of desaturation on phytoene, site-directed mutage-

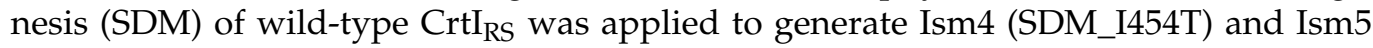
(SDM_A171P). HPLC analysis revealed that the two SDM mutants, Ism4 and Ism5, produced very similar carotenoid profiles to those of RIm1 and RIm2: $14.6 \pm 2.7 \%$ of neurosporene, $79.4 \pm 2.5 \%$ of lycopene, $6 \pm 0.2 \%$ of 3,4-didehydrolycopene in the SDM mutant Ism4, and $19.2 \pm 4.6 \%$ of neurosporene and $80.8 \pm 4.7 \%$ of lycopene without 3,4-didehydrolycopene in the SDM mutant Ism5 (Figure 3a). The very similar carotenoid profiles observed between random mutants and SDM mutants strongly indicate that the single amino acid mutations (I454T and A171P) intrinsically altered the catalytic activity of CrtI $\mathrm{RS}_{\mathrm{S}}$ toward phytoene. Similarly, an SDM mutant (Ism1, SDM_L163P) of the major neurosporene-producing RIm6 (Figure 3a) showed a carotenoid profile very similar to that of RIm6, demonstrating the intrinsically altered catalytic activity of CrtI $I_{R S}$.

a

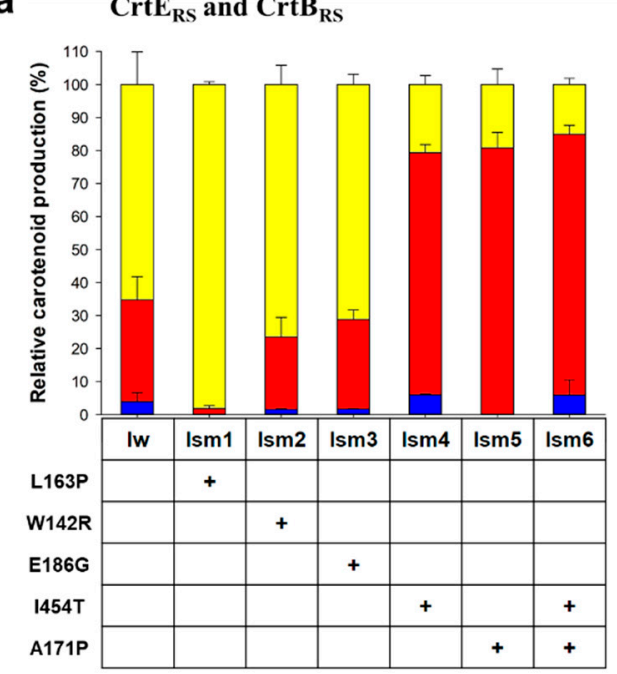

b
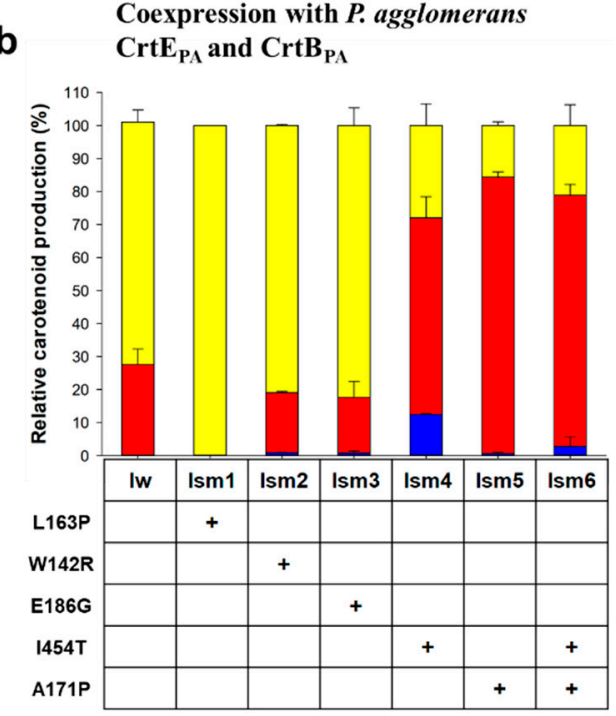
3,4-didehydrolycopene
Lycopene
Neurosporene

Figure 3. Relative carotenoid profiles in E. coli strains coexpressing site-directed mutant $\mathrm{CrtI}_{\mathrm{RS}}$ with (a) the R. sphaeroides $\mathrm{CrtE}_{\mathrm{RS}}$ and $\mathrm{CrtB}_{\mathrm{RS}}$ and (b) the P. agglomerans $\mathrm{CrtE}_{\mathrm{PA}}$ and $\mathrm{CrtB}_{\mathrm{PA}}$. Blue, red, and yellow bars represent 3,4-didehydrolycopene, lycopene, and neurosporene, respectively. Iw refers to a wild-type $\mathrm{CrtI}_{\mathrm{RS}}$. + symbol indicates the amino acid change in the mutant CrtI. Data are expressed as the mean $\pm \mathrm{SD}$.

One additional nucleotide point mutation was observed in the 2nd round mutants RIm3, RIm4, and RIm5. The 2nd single amino acid change of E186G in RIm3 led to double amino acid mutations (I454T and E186G). Similarly, the 2nd single W142R change in RIm5 generated a double amino acid mutation (A171P and W142R). Compared to RIm3 and RIm5, the single nucleotide point mutation in RIm4 caused a silent mutation. Notably, although RIm4 shared a single amino acid A171P mutation with RIm2, except for an additional single silent mutation in RIm4, the two mutants produced different carotenoid profiles (Table 2 and Figure 2a); however, the difference in carotenoid profiles between the two mutants was negligible. 
2.3. Verification of the Effect of E186g and W142r Mutations on Activity of Phytoene Desaturase by Site-Directed Mutagenesis

As RIm3 and RIm5 mutants had additional amino acid mutations (E186G in RIm3 and W142R in RIm5) in comparison with RIm1 (I454T) and RIm2 (A171P) (Table 2). The individual effects of the W142R and E186G mutations were investigated by generating two SDM mutants, Ism2 (SDM_W142R) and Ism3 (SDM_E186G). HPLC analysis revealed that both Ism2 and Ism3 produced slightly less lycopene in comparison with that of

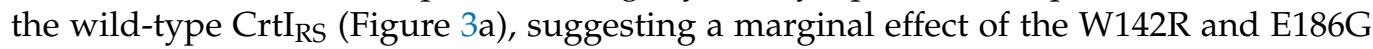
mutations on the degree of phytoene desaturation by RIm3 (E186G and I454T) and RIm5 (W142R and A171P). Since I454T and A171P mutations significantly influenced the degree of desaturation of phytoene, an SDM mutant Ism6 (SDM_I454T_A171P) was generated and its carotenoid profile was investigated. As expected, dramatical alteration of the carotenoid profile (10.1 $\pm 1.9 \%$ of neurosporene, $84.5 \pm 2.7 \%$ of lycopene, and $5.4 \pm 4.6 \%$ of 3,4-didehydrolycopene) was observed in comparison with that of the wild-type CrtI $\mathrm{RS}_{\mathrm{RS}}$ (Figure 3a).

\subsection{Complementation of Mutant Crtirs with the P. agglomerans Crtepa and Crtbpa}

Even though carotenogenic enzymes have the same catalytic function, carotenoid profiles tend to vary depending on the source of the enzymes when expressed in a heterologous host [22]. To better understand the function of the mutant $\mathrm{CrtI}_{\mathrm{RS}}$, random and SDM mutants were coexpressed in E. coli with the heterologous P. agglomerans $\mathrm{CrtE}_{\mathrm{PA}}$ and $\mathrm{CrtB}_{\mathrm{PA}}$. HPLC analysis revealed that the three single amino acid mutants (RIm1, RIm2, and RIm6) when coexpressed with the heterologous $\mathrm{CrtE}_{\mathrm{PA}}$ and $\mathrm{CrtB}_{\mathrm{PA}}$ produced carotenoid profiles similar to those of RIm1, RIm2, and RIm6 when coexpressed with the native CrtB RS $_{\text {. }}$ and $\mathrm{CrtE}_{\mathrm{RS}}$ (Table 2 and Figure 2b); however, RIm3, RIm5 (two double amino acid mutants) and RIm6 (a single amino acid mutant) when coexpressed with the heterologous $\mathrm{CrtE}_{\mathrm{PA}}$ and $\mathrm{CrtB}_{\mathrm{PA}}$ produced different carotenoid profiles in comparison with those coexpressed with native $\mathrm{CrtB}_{\mathrm{RS}}$ and $\mathrm{CrtE}_{\mathrm{RS}}$ (Table 2 and Figure $2 \mathrm{~b}$ ). This suggests that the $2 \mathrm{nd}$ amino acid alteration of E186G in RIm3 and W142R in RIm5 might influence the conformation of the enzyme complex structure, which consequently alters the catalytic activity of mutant $\mathrm{CrtI}_{\mathrm{RS}}$ toward phytoene. Notably, unlike the single amino acid mutants (RIm1, RIm2, and RIm6), RIm4 produced different carotenoid profiles when coexpressed with heterologous and native CrtE and CrtB. Three SDM mutants Ism2 (SDM_W142R), Ism3 (SDM_E186G), and Ism6 (SDM_I454T_A171P) produced similar carotenoid profiles when coexpressed with heterologous and native $\mathrm{CrtE}$ and $\mathrm{CrtB}$ (Figure $3 \mathrm{~b}$ ).

\subsection{Structural Evaluation of Mutant Crtirs Using Computational Model Analysis}

To understand the correlation between the structural changes and the observed activity of mutant $\mathrm{CrtI}_{\mathrm{RS}}$, an in silico model of $\mathrm{CrtI}_{\mathrm{RS}}$ was created using the I-TASSER program [29] with the Protein Data Bank (PDB) templates of Nonlabens dokdonensis DSW- $6 \gamma$-carotenoid desaturase (4REP, [30]) and Pantoea ananatis phytoene desaturase (4DGK, [18]) (Figure 4a). As FAD, a redox-active cofactor, is present in the active site region of $\mathrm{CrtI}_{\mathrm{RS}}$, in silico ligand docking was simulated using COACH-D [31] with the PDB of FAD binding residues of Pseudomonas savastanoi pv. phaseolicola oxidoreductase. Predicted FAD binding sites of $\mathrm{CrtI}_{\mathrm{RS}}$ were the residues 16-17, 19-21, 40-42, 47-49, 61-65, 251-523, 282-284, 287, $315,385,433,476-477,483-485$, and 488 (blue in Figures $4 \mathrm{~b}$ and 5a). Interestingly, the five mutated amino acids of $\mathrm{CrtI}_{\mathrm{RS}}$ (Trp142, Leu163, Ala171, Glu186, and Ile454) were present in the putative membrane-binding domain (red in Figure 5a and blue in Figure $5 b$ ). The membrane-binding domain was previously predicted to influence the hydrophobic residues (cyan in Figure 5a), which are involved in the FAD-associated tunnel of CrtI from $P$. ananatis [18]; therefore, different degrees of phytoene desaturation (the observed differences in carotenoid profiles) in mutant $\mathrm{CrtI}_{\mathrm{RS}}$ could be attributed to the alteration of the FAD binding environment in the active site region of $\mathrm{CrtI}_{\mathrm{RS}}$. 
a

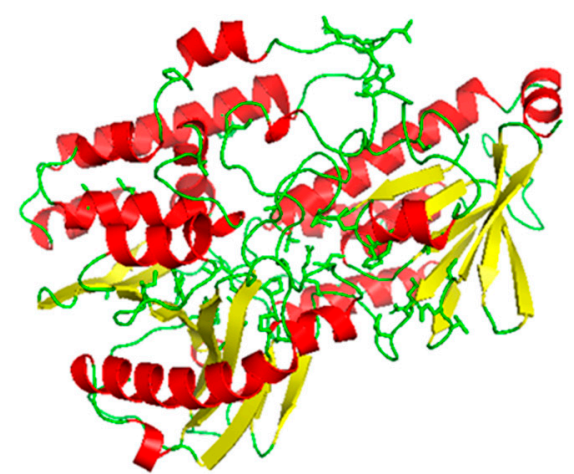

b

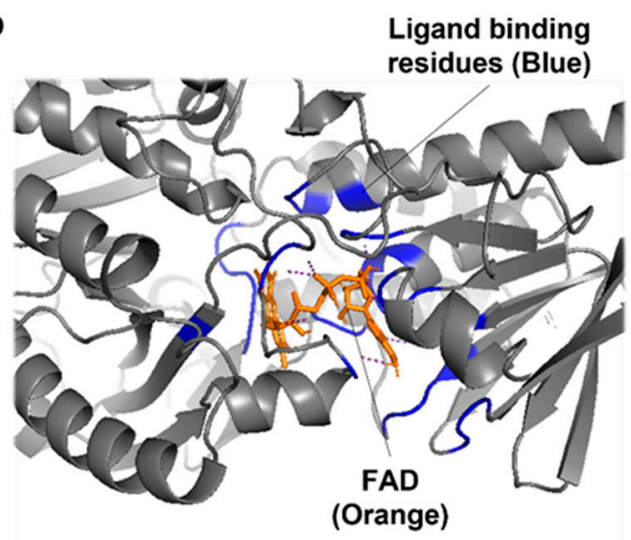

Figure 4. The in-silico-predicted structure of $\mathrm{CrtI}_{\mathrm{RS}}(\mathbf{a})$ and partial view of molecular docking with FAD (b). The FAD ligand binding residues are shown in blue and FAD is shown in orange.
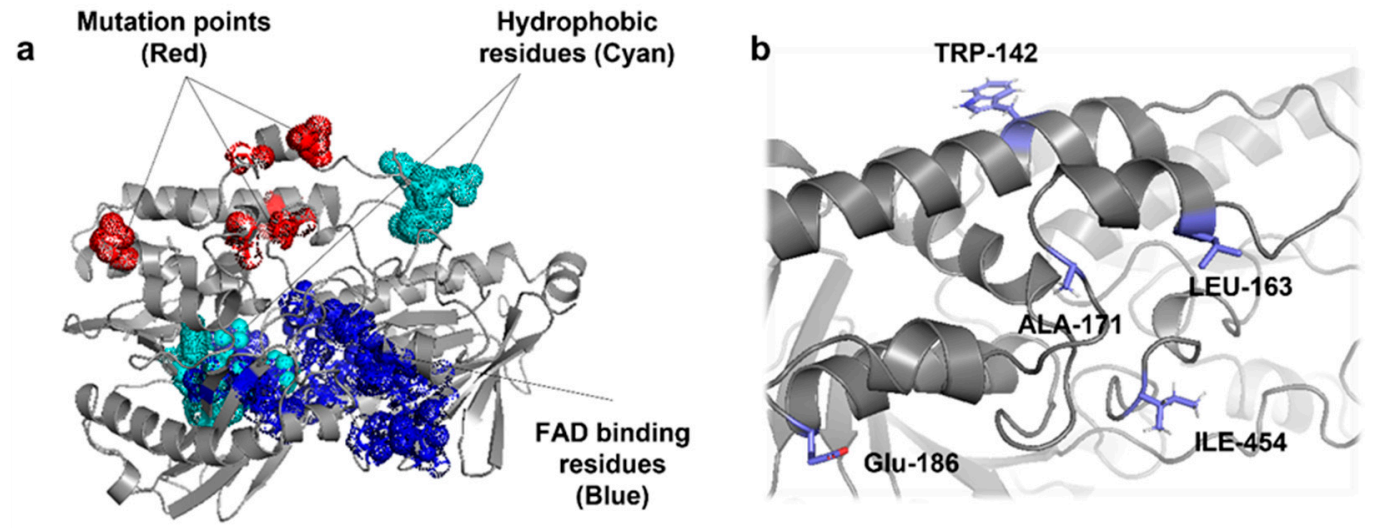

Figure 5. The in-silico-predicted structure of FAD binding residues and hydrophobic residues in $\mathrm{CrtI}_{\mathrm{RS}}(\mathbf{a})$ and five amino acid mutation sites of $\mathrm{CrtI}_{\mathrm{RS}}(\mathbf{b})$.

\section{Materials and Methods}

\subsection{Strains, Plasmids, and Culture Conditions}

All strains and plasmids used in this study are listed in Table 1. E. coli XL-Blue was grown in Luria-Bertani (LB, $10 \mathrm{~g} / \mathrm{L}$ tryptone, $5 \mathrm{~g} / \mathrm{L}$ yeast extract, $5 \mathrm{~g} / \mathrm{L} \mathrm{NaCl}$ ) or M9 minimal medium (2 g/L glucose, $3 \mathrm{~g} / \mathrm{L} \mathrm{KH}_{2} \mathrm{PO}_{4}, 0.5 \mathrm{~g} / \mathrm{L} \mathrm{NaCl}, 6 \mathrm{~g} / \mathrm{L} \mathrm{Na}{ }_{2} \mathrm{HPO}_{4}$, $1 \mathrm{~g} / \mathrm{L} \mathrm{NH}_{4} \mathrm{Cl}, 0.5 \mathrm{~g} / \mathrm{L} \mathrm{CaCl}^{2}, 0.5 \mathrm{~g} / \mathrm{L} \mathrm{MgSO}_{4}$ ). Genomic DNA of $R$. sphaeroides KCTC 12085 grown in LB medium was isolated using the genomic DNA extraction kit GeneAll ${ }^{\circledR}$ Exgene $^{\mathrm{TM}}$ cell SV mini (GeneAll, Seoul, South Korea). The $c r t E$ gene (encoding GGPP synthase), $c r t B$ (phytoene synthase), and $c r t I$ (phytoene desaturase) were amplified from genomic DNA by PCR using gene-specific primers (Table 3 ) and cloned into the pGEM $^{\circledR}$ Teasy vector (Promega Corporation, Madison, WI, USA), resulting in $\mathrm{pT}$ _crtE $\mathrm{RS}_{\mathrm{RS}} \mathrm{pT}_{-} \mathrm{crt} \mathrm{B}_{\mathrm{RS}}$,

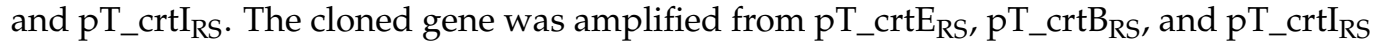
by PCR, then subcloned into the constitutive expression vector $\mathrm{pUCM}$ [22], generating pUCM_E $E_{R S}, p U C M \_B_{R S}$, and $p U C M \_I_{R S}$. To assemble the individual expression modules of the $c r t E, c r t B$, and $c r t I$ genes on $\mathrm{PUCM}$, each gene module was amplified by PCR and subsequentially cloned into pACM plasmid, generating pACM- $E_{R S}, p A C M-E_{R S}-B_{R S}$, and pACM-E $E_{R S}-B_{R S}-I_{R S}$. 
Table 3. Primers used in this study. The underlined sections indicate restriction enzyme sites.

\begin{tabular}{|c|c|c|}
\hline Gene & Primer Sequence & Enzyme Site \\
\hline $\operatorname{crt} E$ & F: $5^{\prime}$ GCTCTAGAAGGAGGATTACAAAATGGCGTTTGAACAGCGGATTG 3' & $\begin{array}{c}\text { XbaI } \\
\text { EcoRI }\end{array}$ \\
\hline $\operatorname{crtB}$ & F: $5^{\prime}$ GGAATTCAGGAGGATTACAAAATGATTGCCTCTGCCGATCT3' & $\begin{array}{l}\text { EcoRI } \\
\text { NcoI }\end{array}$ \\
\hline crtI & F: $5^{\prime}$ GCTCTAGAAGGAGGATTACAAAATGCCCTCGATCTCGCCC $3^{\prime}$ & $\begin{array}{c}\mathrm{XbaI} \\
\mathrm{EcoRI}\end{array}$ \\
\hline
\end{tabular}

\subsection{Error-Prone PCR Mutagenesis}

Random mutagenesis of the R. sphaeroides crtI gene on the plasmid pUCM was performed using a previously reported error-prone PCR method [28]. Briefly, the mutagenic PCR condition of $1.5 \mathrm{mM} \mathrm{MgCl}$, unbalanced dNTP ratio (ATP:TTP:CTP:GTP, 1:1:1:4), and Taq polymerase were utilized to incorporate mismatched bases into the $\mathrm{crtI}$ gene with primers $\left(5^{\prime}\right.$-GCTCTAGAAGGATTACAAAATGCCCTCGATCTCGCCC- ${ }^{\prime}$ and $5^{\prime}$-CGGAATTCTCATTCCGCGGCAAGCCT-3') flanking the $c r t I$ gene on the $\mathrm{pUCM}$ vector. The PCR products were purified using a gel DNA extraction kit (Macrogen, Inc., Seoul, Korea), followed by digestion with the restriction enzymes EcoRI and XbaI. The fragments were cloned into the corresponding site of vector $\mathrm{PUCM}$ and then transformed into $E$. coli harboring $\mathrm{pACM}-\mathrm{E}_{\mathrm{RS}}-\mathrm{B}_{\mathrm{RS}}$. The cells grown on M9 agar plates were supplemented with ampicillin $(100 \mu \mathrm{g} / \mathrm{mL})$ and chloramphenicol $(50 \mu \mathrm{g} / \mathrm{mL})$ at $37{ }^{\circ} \mathrm{C}$ for $24 \mathrm{~h}$ and then incubated at $20^{\circ} \mathrm{C}$ until colonies developed. Colonies on M9 agar plates were visually screened, and those with color changes were selected and restreaked on LB agar plates to isolate pure colonies. The isolated cells were cultured in LB medium supplemented with ampicillin $(100 \mu \mathrm{g} / \mathrm{mL})$ and chloramphenicol $(50 \mu \mathrm{g} / \mathrm{mL})$, and pUCM plasmids containing the mutagenic $c r t I$ gene were isolated from $1 \%(v / v)$ agarose gel with a gel DNA extraction kit (Macrogen). Mutagenic crtI gene sequences were verified by Sanger sequencing (Macrogen). Fresh transformed E. coli strains harboring pACM-E $\mathrm{E}_{\mathrm{RS}}-\mathrm{B}_{\mathrm{RS}}$ and $\mathrm{pUCM}$ _mutant_crtI were prepared and cultured in Terrific Broth $(12 \mathrm{~g} / \mathrm{L}$ tryptone, $24 \mathrm{~g} / \mathrm{L}$ yeast extract, $0.17 \mathrm{M}$ $\mathrm{KH}_{2} \mathrm{PO}_{4}, 0.72 \mathrm{M} \mathrm{K}_{2} \mathrm{HPO}_{4}$, and $10 \mathrm{~g} / \mathrm{L}$ glycerol $)$ supplemented with ampicillin $(100 \mu \mathrm{g} / \mathrm{mL})$ and chloramphenicol $(50 \mu \mathrm{g} / \mathrm{mL})$ to investigate the carotenoid profile.

\subsection{Site-Directed Mutagenesis}

Phusion High-Fidelity DNA Polymerase (New England BioLabs, Inc., Ipswich, MA, USA) was used to perform SDM of the crtI gene. Mutagenesis primers were designed according to the desired crtI gene mutations. After PCR amplification, the PCR product was digested with $D p n I$ for $5 \mathrm{~h}$ and transformed into E. coli. The sequence changes in SDM were verified by Sanger sequencing (Macrogen).

\subsection{Analysis of Carotenoid Production}

Carotenoid extraction was performed using a previously described extraction method [22]. Briefly, $50 \mathrm{~mL}$ of culture was harvested and separated into a cell pellet and culture medium. Carotenoids were repeatedly extracted with a total of $20 \mathrm{~mL}$ of acetone until all visible color disappeared from the cell pellet. Equal volumes of water and hexane were added to the acetone extract and vortex-mixed. The upper carotenoid-containing solvent layer was carefully collected and dehydrated with $0.1 \mathrm{~g}$ anhydrous sodium sulfate (Sigma-Aldrich, St-Louis, MO, USA) for $20 \mathrm{~min}$. After centrifugation $\left(4^{\circ} \mathrm{C}\right.$ and $\left.13,000 \mathrm{rpm}\right)$, the supernatant was collected and completely dried using a Genevac EZ2 centrifugal evaporator (Genevac, Inc., Vally Center, NY, USA). The dried residue was resuspended in $500 \mu \mathrm{L}$ acetone and $20 \mu \mathrm{L}$ of aliquot was subjected to an Agilent 1260 series HPLC (Agilent technologies, Palo Alto, CA, USA) system equipped with an Agilent photodiode array detector and Zorbax eclipse XDB-C18 column ( $4.6 \times 150 \mathrm{~mm}$, silica particle, $80 \AA$, $5 \mu \mathrm{m}$; Agilent Technologies). The column temperature was maintained at $35^{\circ} \mathrm{C}$ and the flow rate was $1 \mathrm{~mL} / \mathrm{min}$. 
Acetonitrile, methanol, and isopropanol (80:15:5, $v / v / v)$ were used for isocratic elution. $\mathrm{UV} /$ Vis analysis of neurosporene, lycopene, and 3,4-didehydrolycopene was carried out at wavelengths of $440 \mathrm{~nm}, 470 \mathrm{~nm}$, and $490 \mathrm{~nm}$, respectively. The relative ratio of each carotenoid profile was calculated by comparing the peak area of each carotenoid in the LC chromatogram generated by OpenLab ChemStation ${ }^{\circledR}$ software (Agilent Technologies). The results are expressed as means \pm standard deviations of three replicates.

\subsection{Computational Modeling of Phytoene Desaturase}

To compare the functional differences of mutant CrtI enzymes, protein structures of CrtI mutants were computationally predicted using I-TASSER [29]. Two protein templates were used to construct CrtI protein models: $\gamma$-carotenoid desaturase (PDB ID: 4repA) from N. dokdonensis DSW-6 [30] and phytoene desaturase (PDB ID: 4dgkA) from P. ananatis [18]. Starting with the protein structures, FAD was docked into the crystal structures using COACH-D [31]. The structure of the FAD ligand was prepared using Chemsketch [32] prior to performing docking simulations. The model structures were visualized using the PyMol Molecular Graphics System (ver 2.0.4, Schrödinger, LLC, New York, NY, USA).

\section{Conclusions}

In this study, phytoene desaturase of $R$. sphaeroides $\left(\mathrm{CrtI}_{\mathrm{RS}}\right)$, a catalyst in the 3-step desaturation of phytoene, was randomly mutated to alter its catalytic activity towards phytoene. $\mathrm{CrtI}_{\mathrm{RS}}$ mutants produced different ratios of neurosporene $(9 \mathrm{CDBs}) /$ lycopene (11 CDBs)/3,4-didehydrolycopene (13 CDBs). Leu163, Ala171, and Ile454 were particularly important residues in determining product alteration between neurosporene, lycopene, and 3,4-didehydrolycopene (Table 2). The evaluation of an in silico model of $\mathrm{CrtI}_{\mathrm{RS}}$ concluded that the mutated amino acids were gathered in the membrane-binding domain, which could distantly influence the FAD binding region [18]. As $\mathrm{CrtI}_{R S}$ is a bacterial carotene desaturase, the microenvironment of the cofactor FAD-binding region is important for the desaturation of phytoene catalyzed by a sole CrtI [33]. Although the distant influence of mutated residues on the FAD binding region of $\mathrm{CrtI}_{\mathrm{RS}}$ was demonstrated through the altered activity of mutant $\mathrm{CrtI}_{\mathrm{RS}}$, the mechanism of FAD reoxidation in successive phytoene desaturation requires further investigation. Notably, phytoene desaturation and FAD reoxidation by quinones are separate events in plant-type phytoene desaturase [34]. This can provide insights into how bacterial CrtI simultaneously modulate phytoene desaturation and FAD reoxidation.

Author Contributions: Conceptualization, P.C.L.; methodology, P.C.L.; formal analysis, B.H.C. and S.H.K.; investigation, B.H.C. and S.H.K.; data curation, B.H.C.; writing-original draft preparation, P.C.L. and B.H.C.; writing-review and editing, P.C.L.; visualization, B.H.C.; supervision, P.C.L.; project administration, P.C.L.; funding acquisition, P.C.L. All authors have read and agreed to the published version of the manuscript.

Funding: This research was funded by the National Research Foundation of Korea (grant numbers 2020M3H7A1098288 and 2020M3A9I5037889) and by the Priority Research Centers Program through the National Research Foundation of Korea (grant number 2019R1A6A1A11051471).

Data Availability Statement: All the data are specified within the manuscript.

Conflicts of Interest: The authors declare no conflict of interest and the funders had no role in the design of the study; in the collection, analyses, or interpretation of data; in the writing of the manuscript; or in the decision to publish the results.

\section{References}

1. Rodriguez-Concepcion, M.; Avalos, J.; Bonet, M.L.; Boronat, A.; Gomez-Gomez, L.; Hornero-Mendez, D.; Limon, M.C.; MeléndezMartínez, A.J.; Olmedilla-Alonso, B.; Palou, A.; et al. A global perspective on ca-rotenoids: Metabolism, biotechnology, and benefits for nutrition and health. Prog. Lipid Res. 2018, 70, 62-93. [CrossRef]

2. Maoka, T. Carotenoids as natural functional pigments. J. Nat. Med. 2020, 74, 1-16. [CrossRef] [PubMed] 
3. Maoka, T. Recent progress in structural studies of carotenoids in animals and plants. Arch. Biochem. Biophys. 2009, 483, 191-195. [CrossRef] [PubMed]

4. Carotenoids Volume 4: Natural Functions; Britton, G.; Liaaen-Jensen, S.; Pfander, H. (Eds.) Birkhäuser: Basel, Switzerland, 2008.

5. Maoka, T.; Kuwahara, T.; Narita, M. Carotenoids of sea angels Clione limacina and Paedoclione doliiformis from the per-spective of the food chain. Mar. Drugs 2014, 12, 1460-1470. [CrossRef] [PubMed]

6. Maoka, T.; Nishino, A.; Yasui, H.; Yamano, Y.; Wada, A. Anti-Oxidative Activity of Mytiloxanthin, a Metabolite of Fucoxan-thin in Shellfish and Tunicates. Mar. Drugs 2016, 14, 93. [CrossRef] [PubMed]

7. Bartley, G.; Schmidhauser, T.; Yanofsky, C.; Scolnik, P. Carotenoid desaturases from Rhodobacter capsulatus and Neurospora crassa are structurally and functionally conserved and contain domains homologous to flavoprotein disulfide oxidoreductases. J. Biol. Chem. 1990, 265, 16020-16024. [CrossRef]

8. Kim, S.H.; Park, Y.H.; Schmidt-Dannert, C.; Lee, P.C. Redesign, Reconstruction, and Directed Extension of the Brevibacterium linens C 40 Carotenoid Pathway in Escherichia coli. Appl. Environ. Microbiol. 2010, 76, 5199-5206. [CrossRef]

9. Lee, P.C.; Momen, A.Z.R.; Mijts, B.N.; Schmidt-Dannert, C. Biosynthesis of Structurally Novel Carotenoids in Escherichia coli. Chem. Biol. 2003, 10, 453-462. [CrossRef]

10. Umeno, D.; Tobias, A.V.; Arnold, F.H. Diversifying Carotenoid Biosynthetic Pathways by Directed Evolution. Microbiol. Mol. Biol. Rev. 2005, 69, 51-78. [CrossRef] [PubMed]

11. Gu, Z.; Deming, C.; Yongbin, H.; Zhigang, C.; Feirong, G. Optimization of carotenoids extraction from Rhodobacter sphaeroides. LWT Food Sci. Technol. 2008, 41, 1082-1088. [CrossRef]

12. Schnurr, G.; Schmidt, A.; Sandmann, G. Mapping of a carotenogenic gene cluster from Erwinia herbicola and functional identification of six genes. FEMS Microbiol. Lett. 1991, 78, 157-161. [CrossRef]

13. Yeliseev, A.A.; Kaplan, S. Anaerobic Carotenoid Biosynthesis in Rhodobacter Sphaeroides 2.4.1: $\mathrm{H}_{2} \mathrm{O}$ Is a Source of Oxygen for the 1-methoxy Group of Spheroidene but not for the 2-oxo Group of Spheroidenone. FEBS Lett. 1997, 403, 10-14. [CrossRef]

14. Bartley, G.E.; Scolnik, P.A.; Beyer, P. Two Arabidopsis thaliana carotene desaturases, phytoene desaturase and zeta-carotene desaturase, expressed in Escherichia coli, catalyze a poly-cis pathway to yield pro-lycopene. Eur. J. Biochem. 1999, 259, 396-403. [CrossRef] [PubMed]

15. Chen, Y.; Li, F.; Wurtzel, E.T. Isolation and Characterization of the Z-ISO Gene Encoding a Missing Component of Carotenoid Biosynthesis in Plants. Plant Physiol. 2010, 153, 66-79. [CrossRef] [PubMed]

16. Park, H.; Kreunen, S.S.; Cuttriss, A.J.; DellaPenna, D.; Pogson, B.J. Identification of the Carotenoid Isomerase Provides Insight into Carotenoid Biosynthesis, Prolamellar Body Formation, and Photomorphogenesis. Plant Cell 2002, 14, 321-332. [CrossRef]

17. Sandmann, G. Evolution of carotene desaturation: The complication of a simple pathway. Arch. Biochem. Biophys. 2009, 483, 169-174. [CrossRef]

18. Schaub, P.; Yu, Q.; Gemmecker, S.; Poussin-Courmontagne, P.; Mailliot, J.; McEwen, A.G.; Ghisla, S.; Al-Babili, S.; Cavarelli, J.; Beyer, P. On the Structure and Function of the Phytoene Desaturase CRTI from Pantoea ananatis, a Membrane-Peripheral and FAD-Dependent Oxidase/Isomerase. PLoS ONE 2012, 7, e39550. [CrossRef]

19. Misawa, N.; Nakagawa, M.; Kobayashi, K.; Yamano, S.; Izawa, Y.; Nakamura, K.; Harashima, K. Elucidation of the Erwinia uredovora carotenoid biosynthetic pathway by functional analysis of gene products expressed in Escherichia coli. J. Bacteriol. 1990, 172, 6704-6712. [CrossRef]

20. Hausmann, A.; Sandmann, G. A single five-step desaturase is involved in the carotenoid biosynthesis pathway to be-ta-carotene and torulene in Neurospora crassa. Fungal Genet. Biol. 2000, 30, 147-153. [CrossRef]

21. Sandmann, G. Combinatorial Biosynthesis of Carotenoids in a Heterologous Host: A Powerful Approach for the Biosynthesis of Novel Structures. ChemBioChem 2002, 3, 629-635. [CrossRef]

22. Song, G.H.; Kim, S.H.; Choi, B.H.; Han, S.J.; Lee, P.C. Functional complementation of heterologous carotenoid biosynthetic enzymes and their effect on carotenoid profiles in Escherichia coli. Appl. Environ. Microbiol. 2013, 79, 610-618. [CrossRef] [PubMed]

23. Choi, B.H.; Hwang, H.J.; Lee, J.E.; Oh, S.H.; Hwang, J.S.; Lee, B.Y.; Lee, P.C. Microbial production of retinyl palmitate and its application as a cosmeceutical. Antioxidants 2020,9, 1130. [CrossRef]

24. Choi, B.H.; Kim, J.H.; Choi, S.Y.; Han, S.J.; Lee, P.C. Redesign and reconstruction of a mevalonate pathway and its application in terpene production in Escherichia coli. Bioresour. Technol. Rep. 2019, 7, 100291. [CrossRef]

25. Han, M.; Lee, P. Microbial Production of Bioactive Retinoic Acid Using Metabolically Engineered Escherichia coli. Microorganisms 2021, 9, 1520. [CrossRef] [PubMed]

26. Lee, J.H.; Kim, J.W.; Lee, P.C. Complete genome sequence of Flavobacterium kingsejongi WV39, a type species of the genus Flavobacterium and a microbial C40 carotenoid zeaxanthin producer. J. Biotechnol. 2018, 266, 9-13. [CrossRef] [PubMed]

27. Lee, J.H.; Kim, J.W.; Lee, P.C. Genome mining reveals two missing CrtP and AldH enzymes in C30 carotenoid bio-synthesis pathway of Planococcus faecalis AJ003T. Molecules 2020, 25, 5892. [CrossRef]

28. Kim, S.H.; Kim, M.S.; Lee, B.Y.; Lee, P.C. Generating structurally novel short carotenoids and studying their biological activity. Sci. Rep. 2016, 6, 21987. [CrossRef] [PubMed]

29. Roy, A.; Kucukural, A.; Zhang, Y. I-TASSER: A unified platform for automated protein structure and function prediction. Nat. Protoc. 2010, 5, 725-738. [CrossRef]

30. Ahn, J.-W.; Kim, K.-J. Crystal structure of 1'-OH-carotenoid 3,4-desaturase from Nonlabens dokdonensis DSW-Enzym. Microb. Technol. 2015, 77, 29-37. [CrossRef] 
31. Wu, Q.; Peng, Z.; Zhang, Y.; Yang, J. COACH-D: Improved protein-ligand binding sites prediction with refined lig-and-binding poses through molecular docking. Nucleic Acids Res. 2018, 46, W438-W442. [CrossRef]

32. Österberg, T.; Norinder, U. Prediction of drug transport processes using simple parameters and PLS statistics The use of ACDlogP and ACDChemSketch descriptors. Eur. J. Pharm. Sci. 2001, 12, 327-337. [CrossRef]

33. Armstrong, G.A.; Alberti, M.; Hearst, J.E. Conserved enzymes mediate the early reactions of carotenoid biosynthesis in nonphotosynthetic and photosynthetic prokaryotes. Proc. Natl. Acad. Sci. USA 1990, 87, 9975-9979. [CrossRef] [PubMed]

34. Brausemann, A.; Gemmecker, S.; Koschmieder, J.; Ghisla, S.; Beyer, P.; Einsle, O. Structure of Phytoene Desaturase Provides Insights into Herbicide Binding and Reaction Mechanisms Involved in Carotene Desaturation. Structure 2017, 25, 1222-1232. [CrossRef] [PubMed] 